\title{
Comparison of prolonged postoperative ileus between laparoscopic right and left colectomy under enhanced recovery after surgery: a propensity score matching analysis
}

Zhenmeng Lin ${ }^{1}$, Chunkang Yang ${ }^{1}$, Yi Wang ${ }^{1}$, Mingfang Yan ${ }^{1}$ and Huizhe Zheng ${ }^{2 *}$

\begin{abstract}
Background: There were differences in the recovery of bowel function and prolonged postoperative ileus (PPOI) between laparoscopic right colectomy (RC) and left colectomy $(\mathrm{LC})$ under the guidance of enhanced recovery after surgery.

Methods: We selected 870 patients who underwent elective laparoscopic colectomy from June 2016 to December 2021, including 272 patients who had RC and 598 who had LC. According to 1:1 proportion for propensity score matching and correlation analysis, 247 patients who had RC and 247 who had LC were finally enrolled.

Results: The incidence of PPOI in all patients was $13.1 \%$. Age, sex, smoking habit, preoperative serum albumin level, operation type, and operation time were the important independent risk factors based on multivariate logistic regression and correlation analysis for PPOI $(p<0.05)$. Age, sex, body mass index, preoperative serum albumin level, operation time, and degree of differentiation between the two groups were significantly different before case matching $(p<0.05)$. There were no statistically significant differences in baseline characteristics and preoperative biochemical parameters between the two groups after case matching ( $p>0.05)$. The incidence of PPOI in patients who had RC was $21.9 \%$, while that in patients who had LC was $13.0 \%$. The first flatus, first semi-liquid, and length of stay in LC patients were lower than those in $\mathrm{RC}$ patients $(p<0.05)$.

Conclusion: The return of bowel function in LC was faster than that in $\mathrm{RC}$, and the incidence of PPOI was relatively lower. Therefore, caution should be taken during the early feeding of patients who had laparoscopic RC.
\end{abstract}

Keywords: Enhanced recovery after surgery, Prolonged postoperative ileus, Laparoscopic colectomy, Colon cancer

\footnotetext{
*Correspondence: zhenghz_1170@163.com

${ }^{2}$ Department of Anesthesiology Surgery, Fujian Medical University

Cancer Hospital \& Fujian Cancer Hospital, No 420 fuma road, Jin'an district, Fuzhou, China

Full list of author information is available at the end of the article
}

\begin{abstract}
Introduction
Postoperative ileus (POI) is defined as an inevitable, temporary decrease in gastrointestinal motility following major abdominal surgery. The average gut dysmotility is widely reported to last $0-24 \mathrm{~h}$ in the small intestine, 24-48 $\mathrm{h}$ in the stomach, and $48-72 \mathrm{~h}$ in the colon $[1,2]$. Prolonged postoperative ileus (PPOI) is a gastrointestinal function that does not recover beyond this time. The
\end{abstract} original author(s) and the source, provide a link to the Creative Commons licence, and indicate if changes were made. The images or other third party material in this article are included in the article's Creative Commons licence, unless indicated otherwise in a credit line to the material. If material is not included in the article's Creative Commons licence and your intended use is not permitted by statutory regulation or exceeds the permitted use, you will need to obtain permission directly from the copyright holder. To view a copy of this licence, visit http://creativecommons.org/licenses/by/4.0/. The Creative Commons Public Domain Dedication waiver (http://creativeco mmons.org/publicdomain/zero/1.0/) applies to the data made available in this article, unless otherwise stated in a credit line to the data. 
principal manifestation of PPOI is nausea and vomiting, abdominal distension, pain, inability to eat or drink, and delayed passage of flatus and stool, which lead to increased postoperative complications, slow rehabilitation, extended length of hospital stay, aggravating financial burden, and increased mortality risk $[3,4]$.

The enhanced recovery after surgery (ERAS) program aims to promote early feeding and progressive patient mobilization, shorten the length of hospital stay, and improve the quality of life of patients without affecting the overall survival and relapse-free survival [5-7]. ERAS has been rapidly popularized and applied in recent years. In 2017, the American Society of Colon and Rectal Surgeons (ASCRS) and the Society of American Gastrointestinal and Endoscopic Surgeons (SAGES) jointly released the clinical practice guideline of ERAS in colorectal surgery to provide important references and guidance for clinical work [8]. There are obvious differences in clinicopathological features, molecular biology, histological features, and prognosis between left and right colon tumors $[9,10]$. Moreover, there are differences in the return of bowel function and complications after surgery [11]. However, the ERAS clinical practice guideline does not distinguish between right colectomy (RC) and left colectomy (LC). Therefore, the present study aimed to compare the incidence of PPOI and postoperative return of bowel function between laparoscopic RC and LC with the ERAS protocol.

\section{Methods}

\section{Patients}

Patients who underwent elective laparoscopic colectomy at Fujian Cancer Hospital from June 2016 to December 2021 were selected for the study. The inclusion criteria were as follows: (1) pathologically confirmed colon cancer; (2) radical resection; (3) adequate implementation of more than $70 \%$ compliance with the ERAS protocol (The ERAS pathway is shown in Table 1); and (4) complete clinical characteristics. The exclusion criteria were as follows: (1) emergency surgery for preoperative intestinal hemorrhage and ileus; (2) multi-organ resection combined with colorectal cancer; (3) mental disturbance; (4) temporary ileostomy; and (5) conversion to open surgery during the operation.

\section{Definitions}

$\mathrm{RC}$ is defined as the removal of the terminal ileum and the ascending right colon followed by an ileo-colonic anastomosis, including cecal, ascending, and hepatic flexure colon cancers.

LC is defined as the resection of the descending colon or the sigmoid colon followed by a colo-colonic anastomosis, including splenic flexure, descending, sigmoid, and rectosigmoid junction colon cancers [12, 13]. During the study period, 870 patients with colon cancer were included as research subjects, including 598 who had LC and 272 who had RC.

The definition of PPOI has not been unified yet. According to references, PPOI is defined as meeting two or more of the following criteria, which were assessed on or after the fourth day of the postoperative period [14, 15]: 1 . nausea or vomiting, 2 . inability to tolerate an oral diet over the last $24 \mathrm{~h}, 3$. abdominal distention, 4 . absence of flatus over the last $24 \mathrm{~h}$, and 5. ileus noted on plain abdominal films or computed tomography scans.

\section{Statistical analysis}

The SPSS 24.0 software was used for all statistical analyses. The continuous data were evaluated using the Student's test or Mann-Whitney $U$ test. The chi-square test was used to compare the count data of the two groups. Univariate analysis was performed to identify risk factors associated with PPOI. Variables with $p<0.05$ in the univariate analyses were analyzed in the subsequent multivariable logistic regression model. The nearest neighbor matching method was used for 1:1 matching, and the caliper value was 0.05 . Statistical significance was set at $p<0.05$.

\section{Results}

\section{Postoperative outcomes of patients}

PPOI occurred in $13.1 \%(114 / 870)$ of all patients with colon cancer. The average length of postoperative hospital stay in patients with PPOI was $8.6 \pm 2.5$ days, which was significantly longer than the $6.3 \pm 1.1$ days in patients without no PPOI before case matching $(t=12.049$, $p=0.000$ ).

\section{Univariate and multivariate analysis of PPOI risk factors in colon cancer}

Among the same background and comorbidity measures, sex, age, smoking habit, preoperative serum albumin level, operation type, and operation time were associated with PPOI (Table 2). All these variables were entered in the multivariate logistic regression model. Multivariate analysis found the following independent risk factors for PPOI: sex (odds ratio $[\mathrm{OR}]=2.242)$, age $(\mathrm{OR}=0.935)$, smoking habit $(\mathrm{OR}=1.732)$, preoperative serum albumin level ( $\mathrm{OR}=1.072)$, operation type $(\mathrm{OR}=2.193)$, and operation time $(\mathrm{OR}=2.205)$ (Table 3$)$.

\section{Comparison of the type of surgical procedure of patients who had RC}

The occurrence probability of PPOI in patients who had laparoscopic right colectomy (LRC) was higher than that in patients who had totally laparoscopic 


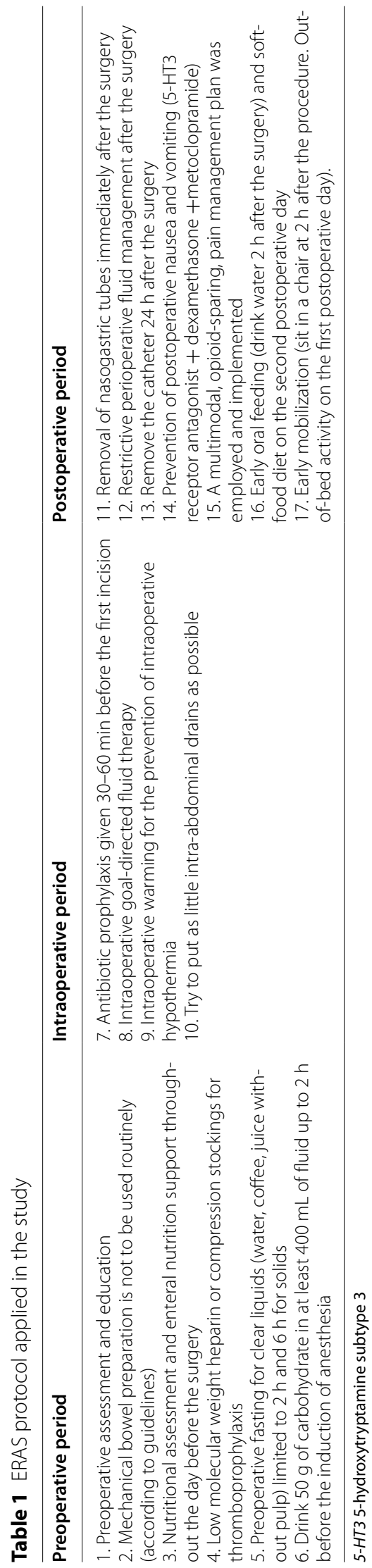


Table 2 Univariate analysis for PPOI risk factors in colon cancer

\begin{tabular}{|c|c|c|c|c|}
\hline Variable & PPOI $(n=114)$ & NO PPOI $(n=756)$ & Univariate OR $(95 \% \mathrm{Cl})$ & $p$ value \\
\hline Sex & & & $1.923(1.242-2.977)$ & 0.003 \\
\hline Male & 83 & 440 & & \\
\hline Female & 31 & 316 & & \\
\hline Age (years) & $64.4 \pm 10.3$ & $55.6 \pm 12.0$ & $0.932(0.913-0.950)$ & 0.000 \\
\hline Diabetes mellitus & & & $0.777(0.517-1.170)$ & 0.227 \\
\hline No & 71 & 514 & & \\
\hline Yes & 43 & 242 & & \\
\hline Hypertension & & & $0.859(0.569-1.296)$ & 0.469 \\
\hline No & 73 & 510 & & \\
\hline Yes & 41 & 246 & & \\
\hline Smoking habit & & & $1.830(1.211-2.766)$ & 0.004 \\
\hline No & 71 & 568 & & \\
\hline Yes & 43 & 188 & & \\
\hline Current alcohol use & & & $0.774(0.511-1.172)$ & 0.227 \\
\hline No & 74 & 533 & & \\
\hline Yes & 40 & 223 & & \\
\hline Previous abdominal surgery & & & $0.741(0.438-1.254)$ & 0.264 \\
\hline No & 94 & 653 & & \\
\hline Yes & 20 & 103 & & \\
\hline Chronic obstructive pulmonary disease & & & $0.723(0.412-1.269)$ & 0.258 \\
\hline No & 97 & 671 & & \\
\hline Yes & 17 & 85 & & \\
\hline $\mathrm{BMI}\left(\mathrm{kg} / \mathrm{m}^{2}\right)$ & $22.8 \pm 2.5$ & $23.1 \pm 3.2$ & $1.043(0.977-1.113)$ & 0.207 \\
\hline Preoperative anemia & & & $0.817(0.532-1.256)$ & 0.358 \\
\hline No & 79 & 555 & & \\
\hline Yes & 35 & 201 & & \\
\hline Preoperative serum albumin level $(\mathrm{g} / \mathrm{L})$ & $37.7 \pm 3.7$ & $39.0 \pm 4.6$ & $1.070(1.022-1.120)$ & 0.004 \\
\hline ASA score & & & $0.728(0.476-1.114)$ & 0.143 \\
\hline$|-| \mid$ & 77 & 560 & & \\
\hline III-IV & 37 & 196 & & \\
\hline Tumor size & & & $0.768(0.517-1.141)$ & 0.191 \\
\hline$<5 \mathrm{~cm}$ & 51 & 388 & & \\
\hline$\geq 5 \mathrm{~cm}$ & 63 & 368 & & \\
\hline Operation type & & & $2.414(1.619-3.600)$ & 0.000 \\
\hline LC & 58 & 540 & & \\
\hline $\mathrm{RC}$ & 56 & 216 & & \\
\hline Operation time (min) & & & $1.799(1.196-2.707)$ & 0.005 \\
\hline$<180$ & 41 & 380 & & \\
\hline$\geq 180$ & 73 & 376 & & \\
\hline Intraoperative blood loss (ml) & $179.8 \pm 101.6$ & $169.3 \pm 72.7$ & $0.998(0.986-1.011)$ & 0.178 \\
\hline Grade of differentiation & & & $0.997(0.739-1.364)$ & 0.987 \\
\hline Well & 22 & 119 & & \\
\hline Moderate & 56 & 426 & & \\
\hline Poorly & 36 & 211 & & \\
\hline Lymph node resected & $23.5 \pm 9.3$ & $24.3 \pm 9.6$ & $1.010(0.988-1.032)$ & 0.395 \\
\hline pTNM stage & & & $1.022(0.774-1.349)$ & 0.880 \\
\hline 1 & 23 & 124 & & \\
\hline$\|$ & 46 & 354 & & \\
\hline III & 45 & 278 & & \\
\hline
\end{tabular}

PPOI prolonged postoperative ileus, $O R$ odds ratio, $B M I$ body mass index, ASA American Society of Anesthesiologists, $L C$ left colectomy, $R C$ right colectomy 
Table 3 Multivariate analysis of PPOI after colon cancer surgery

\begin{tabular}{|c|c|c|c|c|c|c|}
\hline Parameter & $\beta$ & Std. error & Wald chi-square & $p$ value & Odds ratio & $95 \% \mathrm{Cl}$ for odds ratio \\
\hline Age & -0.068 & 0.011 & 40.126 & 0.000 & 0.935 & $0.915-0.954$ \\
\hline Sex & 0.807 & 0.239 & 11.382 & 0.001 & 2.242 & $1.403-3.583$ \\
\hline Smoking habit & 0.549 & 0.228 & 5.820 & 0.016 & 1.732 & $1.109-2.706$ \\
\hline $\begin{array}{l}\text { Preoperative Serum } \\
\text { albumin level }\end{array}$ & 0.069 & 0.026 & 7.042 & 0.008 & 1.072 & $1.018-1.128$ \\
\hline Operation type & 0.785 & 0.222 & 12.476 & 0.000 & 2.193 & $1.418-3.390$ \\
\hline Operation time & 0.791 & 0.227 & 12.185 & 0.000 & 2.205 & $1.415-3.438$ \\
\hline
\end{tabular}

95\%Cl 95\% confidence interval

right colectomy (TLRC). Compared with LRC, TLRC was associated with shorter first flatus, first semiliquid diet, and postoperative length of stay $(p<0.05)$ (Table 4).

\section{Comparison of general clinicopathological data of patients} who had RC and LC before matching

Compared with patients who had RC, statistical differences were observed in age, sex, body mass index BMI, preoperative serum albumin level, operation time, and grade of differentiation in patients who had LC before case matching. The incidence of PPOI in patients who had RC was $20.6 \%(56 / 272)$, which was higher than the $9.7 \%$ incidence $(58 / 598)$ in patients who had LC. The first flatus, semi-liquid diet, and length of postoperative hospital stay in patients who had $\mathrm{RC}$ were higher than those in patients who had LC (Table 5).

\section{Clinicopathological characteristics after case matching}

To reduce the possibility of selection bias, we conducted propensity score matching. Based on baseline data, the propensity score matching method was conducted with 1:1 matching, and 247 patients were included in each group. The clinicopathological features between the two groups were not statistically significantly different after matching (Table 6).

\section{Comparison of the return of bowel function and length of postoperative hospital stay between the two groups after matching}

The occurrence probability of PPOI in patients who had RC was $21.9 \%$ (54/247), while the occurrence probability of PPOI in patients who had LC was $13.0 \%(32 / 247)$. The time of first flatus, semi-liquid time, and length of postoperative hospital stay in patients who had LC were lower than those in patients who had RC $(p<0.05)$ (Table 7$)$.

\section{Discussion}

Compared with open colectomy, laparoscopic colectomy has many advantages, such as faster postoperative return of bowel function, fewer complications, less pain, fewer hospital stays, and similar long-term effect [16-18]. The clinical practice guideline for enhanced recovery after colon and rectal surgery from the ASCRS and SAGES strongly recommends employing a minimally invasive surgical approach whenever expertise is available and appropriate for colon cancer [8]. Laparoscopic colectomy has been widely recognized worldwide. Since 2016, most patients with curable colon cancer have undergone laparoscopic surgery in our hospital. Patients who underwent laparoscopic surgery were included in this study to eliminate errors and improve the reliability of research.

Murphy et al. [19] studied 9734 patients identified from the colectomy-specific American College of Surgeons National Surgical Quality Improvement Program

Table 4 Comparison of postoperative gastrointestinal function recovery and discharge time between LRC and TLRC

\begin{tabular}{|c|c|c|c|c|}
\hline Group & LRC $(n=181)$ & $\operatorname{TLRC}(n=91)$ & $t / x^{2}$ & $p$ value \\
\hline PPOI & & & 7.707 & 0.005 \\
\hline No & 135 & 81 & & \\
\hline Yes & 46 & 10 & & \\
\hline First flatus (days) & $3.8 \pm 2.6$ & $2.8 \pm 1.9$ & 3.009 & 0.003 \\
\hline First semi-liquid diet (days) & $5.3 \pm 2.6$ & $4.4 \pm 2.0$ & 3.011 & 0.003 \\
\hline Postoperative length of stay (days) & $7.8 \pm 2.8$ & $7.1 \pm 1.7$ & 2.239 & 0.026 \\
\hline
\end{tabular}

$L R C$ laparoscopic right colectomy, TLRC totally laparoscopic right colectomy 
Table 5 Demographic characteristics of patients and postoperative functional recovery before matching

\begin{tabular}{|c|c|c|c|c|}
\hline Variable & LC $(n=598)$ & $\mathrm{RC}(n=272)$ & $t / x^{2}$ & $p$ value \\
\hline Sex & & & 4.073 & 0.044 \\
\hline Male & 373 & 150 & & \\
\hline Female & 225 & 122 & & \\
\hline Age (years) & $55.8 \pm 11.7$ & $58.8 \pm 12.7$ & -3.458 & 0.001 \\
\hline Diabetes mellitus & & & 0.204 & 0.652 \\
\hline No & 405 & 180 & & \\
\hline Yes & 193 & 92 & & \\
\hline Hypertension & & & 0.672 & 0.412 \\
\hline No & 406 & 177 & & \\
\hline Yes & 192 & 95 & & \\
\hline Smoking habit & & & 0.212 & 0.645 \\
\hline Nonsmoker & 442 & 197 & & \\
\hline Smoker & 156 & 75 & & \\
\hline Current alcohol use & & & 0.846 & 0.358 \\
\hline No & 423 & 184 & & \\
\hline Yes & 175 & 88 & & \\
\hline Previous abdominal surgery & & & 0.093 & 0.760 \\
\hline No & 512 & 235 & & \\
\hline Yes & 86 & 37 & & \\
\hline Chronic obstructive pulmonary disease & & & 0.064 & 0.801 \\
\hline No & 529 & 239 & & \\
\hline Yes & 69 & 33 & & \\
\hline BMI $\left(\mathrm{kg} / \mathrm{m}^{2}\right)$ & $23.3 \pm 3.2$ & $22.7 \pm 2.7$ & 2.416 & 0.016 \\
\hline Preoperative anemia & & & 1.826 & 0.177 \\
\hline No & 444 & 190 & & \\
\hline Yes & 154 & 82 & & \\
\hline Preoperative serum albumin level & $39.1 \pm 4.5$ & $38.1 \pm 4.4$ & 3.055 & 0.002 \\
\hline ASA & & & 0.725 & 0.395 \\
\hline$|-I|$ & 443 & 194 & & \\
\hline$\geq \mid 11$ & 155 & 78 & & \\
\hline Tumor size & & & 0.387 & 0.534 \\
\hline$<5 \mathrm{~cm}$ & 306 & 133 & & \\
\hline$\geq 5 \mathrm{~cm}$ & 292 & 139 & & \\
\hline Operation time (min) & & & 5.744 & 0.017 \\
\hline$<180$ & 273 & 148 & & \\
\hline$\geq 180$ & 325 & 124 & & \\
\hline Blood loss (ml) & $168.9 \pm 76.2$ & $174.7 \pm 79.1$ & -1.039 & 0.299 \\
\hline Grade of differentiation & & & 12.860 & 0.002 \\
\hline Well & 92 & 49 & & \\
\hline Moderate & 355 & 127 & & \\
\hline Poorly & 151 & 96 & & \\
\hline Lymph node resected & $23.9 \pm 9.6$ & $24.9 \pm 9.4$ & -1.527 & 0.127 \\
\hline pTNM stage & & & 3.808 & 0.149 \\
\hline । & 103 & 44 & & \\
\hline$\|$ & 262 & 138 & & \\
\hline III & 233 & 90 & & \\
\hline $\mathrm{PPOI}$ & & & 19.470 & 0.000 \\
\hline No & 540 & 216 & & \\
\hline Yes & 58 & 56 & & \\
\hline First flatus & $2.1 \pm 1.8$ & $3.5 \pm 2.4$ & -9.379 & 0.000 \\
\hline First semi-liquid diet & $3.6 \pm 1.8$ & $5.0 \pm 2.5$ & -9.765 & 0.000 \\
\hline Length of stay & $6.2 \pm 1.4$ & $7.6 \pm 2.3$ & -9.674 & 0.000 \\
\hline
\end{tabular}

$L C$ left colectomy, $R C$ right colectomy, BMI body mass index, ASA American Society of Anesthesiologists, $P P O /$ prolonged postoperative ileus 
Table 6 Comparison of the two groups' baseline characteristics after matching

\begin{tabular}{|c|c|c|c|c|}
\hline Variable & LC $(n=247)$ & $\mathrm{RC}(n=247)$ & $t / X^{2}$ & $p$ value \\
\hline Sex & & & 0.206 & 0.650 \\
\hline Male & 143 & 138 & & \\
\hline Female & 104 & 109 & & \\
\hline Age (years) & $57.5 \pm 12.2$ & $59.1 \pm 12.9$ & -1.353 & 0.177 \\
\hline Diabetes mellitus & & & 0.037 & 0.848 \\
\hline No & 166 & 164 & & \\
\hline Yes & 81 & 83 & & \\
\hline Hypertension & & & 0.144 & 0.704 \\
\hline No & 165 & 161 & & \\
\hline Yes & 82 & 86 & & \\
\hline Smoking habit & & & 0.041 & 0.840 \\
\hline Nonsmoker & 180 & 178 & & \\
\hline Smoker & 67 & 69 & & \\
\hline Current alcohol use & & & 0.778 & 0.378 \\
\hline No & 177 & 168 & & \\
\hline Yes & 70 & 79 & & \\
\hline Previous abdominal surgery & & & 0.067 & 0.796 \\
\hline No & 211 & 213 & & \\
\hline Yes & 36 & 34 & & \\
\hline Chronic obstructive pulmonary disease & & & 0.074 & 0.786 \\
\hline No & 215 & 217 & & \\
\hline Yes & 32 & 30 & & \\
\hline $\mathrm{BMI}\left(\mathrm{kg} / \mathrm{m}^{2}\right)$ & $23.1 \pm 3.2$ & $22.7 \pm 2.8$ & 1.511 & 0.131 \\
\hline Preoperative anemia & & & 1.448 & 0.229 \\
\hline No & 184 & 172 & & \\
\hline Yes & 63 & 75 & & \\
\hline Preoperative serum albumin level (g/L) & $38.4 \pm 4.0$ & $38.2 \pm 4.3$ & 0.680 & 0.497 \\
\hline ASA & & & 0.495 & 0.482 \\
\hline$|-| \mid$ & 182 & 175 & & \\
\hline III-IV & 65 & 72 & & \\
\hline Tumor size & & & 0.203 & 0.653 \\
\hline$<5 \mathrm{~cm}$ & 123 & 118 & & \\
\hline$\geq 5 \mathrm{~cm}$ & 124 & 129 & & \\
\hline Operation time (min) & & & 0.980 & 0.322 \\
\hline$<180$ & 115 & 126 & & \\
\hline$\geq 180$ & 132 & 121 & & \\
\hline Blood loss (ml) & $171.4 \pm 86.0$ & $173.7 \pm 79.2$ & -0.305 & 0.760 \\
\hline Grade of differentiation & & & 1.149 & 0.563 \\
\hline Well & 47 & 46 & & \\
\hline Moderate & 119 & 109 & & \\
\hline Poorly & 81 & 92 & & \\
\hline Lymph node resected & $24.3 \pm 11.0$ & $24.9 \pm 9.2$ & -0.652 & 0.515 \\
\hline pTNM stage & & & 1.354 & 0.508 \\
\hline । & 49 & 50 & & \\
\hline$\|$ & 95 & 106 & & \\
\hline III & 103 & 91 & & \\
\hline
\end{tabular}

$L C$ left colectomy, $R C$ right colectomy, $B M I$ body mass index, ASA American Society of Anesthesiologists 
Table 7 Comparison of postoperative gastrointestinal function recovery and discharge time between the two groups

\begin{tabular}{|c|c|c|c|c|}
\hline Group & LC $(n=247)$ & $\mathrm{RC}(n=247)$ & $t / x^{2}$ & $p$ value \\
\hline PPOI & & & 6.814 & 0.009 \\
\hline No & 215 & 193 & & \\
\hline Yes & 32 & 54 & & \\
\hline First flatus (days) & $2.8 \pm 1.7$ & $3.7 \pm 2.4$ & -4.721 & 0.000 \\
\hline First semi-liquid diet (days) & $4.3 \pm 1.7$ & $5.3 \pm 2.4$ & -5.067 & 0.000 \\
\hline Postoperative length of stay (days) & $6.3 \pm 1.5$ & $7.4 \pm 2.2$ & -6.147 & 0.000 \\
\hline
\end{tabular}

$L C$ left colectomy, $R C$ right colectomy, $P P O I$ prolonged postoperative ileus

database who underwent elective surgery. They found that 1364 (14\%) patients had PPOI. Alhashemi et al. [14] found that the incidence of PPOI was 19\% after colorectal surgery in the context of enhanced recovery pathways. The incidence of PPOI is $10.3 \%$ in a meta-analysis comprising 18,983 patients with colon cancer [20]. This is similar to the $13.1 \%$ overall incidence of PPOI in our study. However, a snapshot, prospective, observational study in England showed that the rate of PPOI was as high as $22.5 \%$ after elective colorectal surgery [21]. The reason may be that perioperative management was not performed in accordance with the ERAS guidelines in this study.

As early as 1990, Bufill confirmed the difference between right and left colon cancer from the perspective of molecular genetics and proposed that they can be regarded as distinct disease entities for the first time [22]. Subsequently, a large number of studies showed significant differences between them, such as clinical features, epidemiological features, histological characteristics, molecular biology, treatment, and prognosis [23-25]. In this study, we found statistical differences in age, sex, BMI, preoperative serum albumin level, and grade of differentiation among the two groups. Although not strongly supported by the references, the surgery of $\mathrm{LC}$ is more challenging to perform than that of $\mathrm{RC}$ due to better exposure and intraperitoneal location of the anastomosis, especially when splenic flexure mobilization or rectal mobilization is warranted [26]. In this study, the operation time of $\mathrm{LC}$ was longer than that of $\mathrm{RC}$, indicating that LC surgery may be more difficult.

Although postoperative recovery following colorectal surgery has been well studied, few studies have directly compared the incidence of PPOI and recovery from RC and LC. The first flatus, first semi-liquid diet, and PPOI of patients who had RC are higher than those of patients who had LC. Moreover, this study showed that age, sex, smoking history, smoking habit, preoperative serum albumin level, operation type, and operation time were independent risk factors for PPOI. Therefore, propensity score matching was used to reduce the deviation caused by interference factors and make the baseline characteristics of the two groups more comparable. After matching, the differences in clinicopathologic features between the two groups were not statistically significant. The first flatus, first semi-liquid diet, length of postoperative hospital stays, and PPOI in patients who had RC were higher than those of patients who had LC. It shows that the return of bowel function after RC surgery is slower and the incidence of PPOI is higher than that in patients who had LC. Consistent with previously published studies, Garfinkle et al. [13] conducted a study based on 40,636 patients who had colon surgery in the public database of the American College of Surgeons and concluded that the PPOI of patients who had RC was $35 \%$ higher than the PPOI of those who had LC $(\mathrm{OR}=1.35$, 95\% CI: $1.25-1.47)$. The RC group also had a longer mean length of stay and more 30-day readmissions. Yuan et al. [11] studied 94 consecutive patients undergoing elective colorectal resections with primary anastomosis and found that LC results in a faster return of bowel function than RC. Grass et al. [12] found that the operative time of $\mathrm{LC}$ was longer than that of $\mathrm{RC}$, but the incidence of PPOI in $\mathrm{LC}$ was lower than that in RC.

The pathophysiological mechanism underlying the slower recovery of bowel function and higher incidences of PPOI in RC has not been fully clarified. One possible explanation is that the most distal region of the colon has a specialized "rectosigmoid brake" role, with retrograde cyclic motor patterns (CMPs) occurring prominently after meals at a rate of approximately 2-4 cycles per minute, which limits rectal filling and thereby potentially contributes to continence [27]. A recent manometry study in patients who had $\mathrm{RC}$ showed that the distal colon becomes hyperactive after surgery with CMPs [28]. Another explanation could be that the colonic peristalsis and transit are regulated by the ileocecal valve. The ileocecal valve's loss during RC and bowel disturbances are due to bacterial translocation from the colon to the small intestine $[29,30]$. A third explanation could be the increased trauma to the small bowel associated with an ileocolic anastomosis compared to a more distal anastomosis. Surgical trauma results in a surge in sympathetic and adrenergic motor neuron activity, which 
causes intestinal analysis [31]. Other authors have also cited differences in vagal innervation between the proximal colon (inputs from the brainstem) and distal colon (inputs from pelvic ganglia). It has been proposed that the "pacemaker" regions in the distal colon contribute to the normal regulation of the intestinal transit, and resection of these may lead to accelerated postoperative transit through the distal colon [21].

The surgical procedure for RC is not standardized, including LRC and TLRC. TLRC was associated with significantly faster to first flatus, first semi-liquid diet, and postoperative length of stay, confirming that TLRC leads to faster recovery of bowel functions after surgery. LRC requires extracorporeal anastomosis, while TLRC requires directly intracorporeal anastomosis. TLRC with a lesser bowel mobilization, manipulation, and traction could lead to faster recovery of bowel function [32].

\section{Conclusion}

Although ERAS has been widely accepted and popularized, PPOI remains an incurable complication after colectomy. The return of bowel function in patients who had RC was slower than those who had LC, and the incidence of RC's PPOI was relatively higher. ERAS requires normal oral intake to be restored as soon as possible, but it may be necessary to appropriately extend the fasting time for patients who had RC.

\section{Abbreviations}

POI: Postoperative ileus; PPOI: Prolonged postoperative ileus; ERAS: Enhanced recovery after surgery; ASCRS: American Society of Colon and Rectal Surgeons; SAGES: Society of American Gastrointestinal and Endoscopic Surgeons; RC: Right colectomy; LC: Left colectomy; OR: Odds ratio; CMPs: Cyclic motor patterns.

\section{Acknowledgements}

The authors would like to thank the Fujian Cancer Hospital (Department of Gastrointestinal Surgery) for collecting the data of the patients.

\section{Authors' contributions}

Zhenmeng Lin analyzed the data and wrote the paper. Chunkang Yang designed the study and provided clinical advice. Yi Wang and Mingfang Yan conducted the literature search and collected the clinical data. Huizhe Zheng designed the study and supervised the statistical data. The author(s) read and approved the final manuscript.

\section{Funding}

This work was supported by the Startup Fund for scientific research, Fujian Medical University (Grant number:2018QH1231,2019QH1199), Fujian Provincial Health Technology Project (Grant number:2021TG015).

\section{Availability of data and materials}

Data are available on request from the authors.

\section{Declarations}

Ethics approval and consent to participate

This study protocol was approved by the Clinical Research Ethics Committee of Fujian Cancer Hospital. All patients signed informed consent.
Consent for publication

Not applicable

\section{Competing interests}

The authors declare that they have no competing interests.

\section{Author details}

${ }^{1}$ Department of Gastrointestinal Surgery, Fujian Medical University Cancer Hospital \& Fujian Cancer Hospital, No 420 fuma road, Jin' an district, Fuzhou, China. ${ }^{2}$ Department of Anesthesiology Surgery, Fujian Medical University Cancer Hospital \& Fujian Cancer Hospital, No 420 fuma road, Jin' an district, Fuzhou, China.

Received: 17 January 2022 Accepted: 3 February 2022

Published online: 04 March 2022

\section{References}

1. Vather R, Trivedi S, Bissett I. Defining postoperative ileus: results of a systematic review and global survey. J Gastrointest Surg. 2013;17:962-72.

2. Bragg D, El-Sharkawy AM, Psaltis E, et al. Postoperative ileus: Recent developments in pathophysiology and management. Clin Nutr. 2015:34(3):367-76.

3. Mao H, Milne TGE, O'Grady G, et al. Prolonged postoperative ileus significantly increases the cost of inpatient stay for patients undergoing elective colorectal surgery: results of a multivariate analysis of prospective data at a single institution. Dis Colon Rectum. 2019;05,62(5):631-7.

4. Tevis SE, Carchman EH, Foley EF, et al. Postoperative ileus-more than just prolonged length of stay? J Gastrointest Surg. 2015;19(9):1684-90.

5. Ota H, Ikenaga M, Hasegawa J, et al. Safety and efficacy of an "enhanced recovery after surgery" protocol for patients undergoing colon cancer surgery: a multi-institutional controlled study. Surg Today. 2017;:47(6):668-75.

6. Wang B, Wu Z, Zhang R, et al. Retrospective analysis of safety and efficacy of enhanced recovery pathways in stage II-III colorectal cancer patients submitted to surgery and adjuvant therapy. World J Surg Oncol. 2021;19(1):99

7. Viannay $P$, Hamy $A$, Jaouen $R$, et al. Does enhanced recovery improve the survival rates of patients 3 years after undergoing surgery to remove a tumor in the colon? Int J Colorectal Dis. 2019;34(3):441-9.

8. Carmichael JC, Keller DS, Baldini G, et al. Clinical practice guideline for enhanced recovery after colon and rectal surgery from the American Society of Colon and Rectal Surgeons (ASCRS) and Society of American Gastrointestinal and Endoscopic Surgeons (SAGES). Surg Endosc. 2017;31(9):3412-36

9. Jung MK, Shin US, Ki YJ, et al. Is the Location of the Tumor Another Prognostic Factor for Patients With Colon Cancer? Ann Coloproctol. 2017;33(6):210-8.

10. Lee MS, Menter DG, Kopetz S. Right versus left colon cancer 10. biology: integrating the consensus molecular subtypes. J Natl Compr Canc Netw. 2017;15(3):411-9.

11. Yuan $L, O^{\prime} G$ rady $G$, Milne T, et al. Prospective comparison of return of bowel function after left versus right colectomy. ANZ J Surg. 2018;88(4):E242-7.

12. Grass F, Lovely JK, Crippa J, et al. Comparison of recovery and outcome after left and right colectomy. Colorectal Dis. 2019;21(4):481-6.

13. Garfinkle R, Al-Rashid F, Morin N, et al. Are right-sided colectomies for neoplastic disease at increased risk of primary postoperative ileus compared to left-sided colectomies? A coarsened exact matched analysis. Surg Endosc. 2020;34(12):5304-11.

14. Alhashemi M, Fiore JF, Safa N, et al. Incidence and predictors of prolonged postoperative ileus after colorectal surgery in the context of an enhanced recovery pathway. Surg Endosc. 2019;33(7):2313-22.

15. Liang $W Q$, Zhang KC, Li H, et al. Preoperative albumin levels predict prolonged postoperative ileus in gastrointestinal surgery. World I Gastroenterol. 2020;21,26(11):1185-96.

16. Liang $W, L i J$, Zhang $W$, et al. Prolonged postoperative ileus in gastric surgery: Is there any difference between laparoscopic and open surgery? Cancer Med. 2019;09,8(12):5515-23. 
17. Ishibe A, Ota M, Fujii S, et al. Midterm follow-up of a randomized trial of open surgery versus laparoscopic surgery in elderly patients with colorectal cancer. Surg Endosc. 2017;31(10):3890-7.

18. Yang ZF, Wu DQ, Wang JJ, et al. Short-and long-term outcomes following laparoscopic vs open surgery for pathological T4 colorectal cancer: 10 years of experience in a single center. World J Gastroenterol. 2018;24(1):76-86

19. Murphy MM, Tevis SE, Kennedy GD. Independent risk factors for prolonged postoperative ileus development. J Surg Res. 2016:201(2):279-85.

20. Wolthuis AM, Bislenghi G, Fieuws S, et al. Incidence of prolonged postoperative ileus after colorectal surgery: a systematic review and meta-analysis. Colorectal Dis. 2016;18:01-9.

21. Yorkshire Surgical Research Collaborative. Multicentre observational study of gastrointestinal recovery after elective colorectal surgery. Colorectal Dis. 2018;20:536-44.

22. Bufill JA. Colorectal cancer: evidence for distinct genetic categories based on proximal or distal tumor location. Ann Intern Med. 1990;113(10):779-88.

23. Kalantzis I, Nonni A, Pavlakis K, et al. Clinicopathological differences and correlations between right and left colon cancer. World J Clin Cases. 2020;8(8):1424-43.

24. Beltrán L, González-Trejo S, Carmona-Herrera DD, et al. Prognostic factors and differences in survival of right and left colon carcinoma: a strobe compliant retrospective cohort study. Arch Med Res. 2019;50(2):63-70.

25. Helvaci K, Eraslan E, Yildiz F, et al. Comparison of clinicopathological and survival features of right and left colon cancers. J BUON. 2019;24(5):1845-51.

26. Turrado-Rodriguez V, Targarona Soler E, Bollo Rodriguez JM, et al. Are there differences between right and left colectomies when performed by laparoscopy? Surg Endosc. 2016;30(4):1413-8.

27. Lin AY, Du P, Dinning PG, et al. High-resolution anatomic correlation of cyclic motor patterns in the human colon: evidence of a rectosigmoid brake. Am J Physiol Gastrointest Liver Physiol. 2017;312:G508-15.

28. Seo SHB, Bissett I. O'Grady G, et al. Variable gut function recovery after right vs. left colectomy may be due to rectosigmoid hyperactivity. Front Physiol. 2021;12:635167.

29. Ibañez N, Abrisqueta J, Luján J, et al. Isoperistaltic versus antiperistaltic side-to-side anastomosis after right laparoscopic hemicolectomy for cancer (ISOVANTI) trial: study protocol for a randomised clinical trial. Int J Colorectal Dis. 2017;32(9):1349-56.

30. Foloranmi S, Rakoczy G, Bruce J, et al. Ileocaecal valve:how important is it? Pediatr Surg Int. 2011;27:613-5.

31. Boeckxstaens GE, de Jonge WJ. Neuroimmune mechanisms in postoperative ileus. Gut. 2009:58:1300-11.

32. Zhang M, Lu Z, Zheng Z, et al. Comparison of short-term outcomes between totally laparoscopic right colectomy and laparoscopic-assisted right colectomy: a retrospective study in a single institution on 300 consecutive patients. Surg Endosc. 2022;36(1):176-84.

\section{Publisher's Note}

Springer Nature remains neutral with regard to jurisdictional claims in published maps and institutional affiliations.

Ready to submit your research? Choose BMC and benefit from:

- fast, convenient online submission

- thorough peer review by experienced researchers in your field

- rapid publication on acceptance

- support for research data, including large and complex data types

- gold Open Access which fosters wider collaboration and increased citations

- maximum visibility for your research: over $100 \mathrm{M}$ website views per year

At BMC, research is always in progress.

Learn more biomedcentral.com/submissions 